\title{
BMJ Open Relation between otitis media and sensorineural hearing loss: a systematic review
}

\author{
Hester Beatrice Emilie Elzinga, ${ }^{1}$ Hanneke Doremiek van Oorschot (D) , \\ Inge Stegeman (D) , 2,3 Adriana L Smit ${ }^{2,3}$
}

To cite: Elzinga HBE, van Oorschot HD, Stegeman I, et al. Relation between otitis media and sensorineural hearing loss: a systematic review. BMJ Open 2021;11:e050108. doi:10.1136/ bmjopen-2021-050108

- Prepublication history and additional supplemental material for this paper are available online. To view these files, please visit the journal online. (http://dx.doi.org/10.1136/ bmjopen-2021-050108)

HBEE and HDv0 are joint first authors.

Received 16 February 2021 Accepted 26 July 2021

A) Check for updates

C Author(s) (or their employer(s)) 2021. Re-use permitted under CC BY-NC. No commercial re-use. See rights and permissions. Published by BMJ.

${ }^{1}$ Otorhinolaryngology and Head \& Neck Surgery, UMC Utrecht, Utrecht, The Netherlands ${ }^{2}$ Department of

Otorhinolaryngology, Head and Neck Surgery, UMC Utrecht, Utrecht, The Netherlands

${ }^{3}$ Department of Translational Neuroscience, UMC Utrecht Brain Center, Utrecht, The Netherlands

Correspondence to

Dr Adriana L Smit

A.L.Smit-9@umcutrecht.nl

\section{ABSTRACT}

Objectives This systematic review summarises the evidence on the correlation between recurrent acute otitis media (rAOM) or chronic suppurative otitis media (CSOM) and sensorineural hearing loss (SNHL).

Research methods PubMed, Embase and Cochrane Library databases were searched from inception to 15 January 2021. Two authors independently identified articles, extracted data and performed quality assessment for included studies. Studies comparing the sensorineural hearing levels of patients with a history of $\mathrm{rAOM} / \mathrm{CSOM}$ for $>3$ months to a control group were included.

Results Screening of 4168 articles lead to inclusion of two case-control studies (control-group: patients non-OM) and seven cohort-studies (control group: contralateral ear). Quality assessment indicated considerable risk of bias in all studies. Reported populations varied (sample size 13-607, mean age 22-41.5 years, mean duration of disease 6.1-12.4 years). The OR for SNHL in the OMgroup was $3.30-7.86(95 \% \mathrm{Cl} 1.16$ to $9.40, \mathrm{p}<0.05)$ in cohort studies $(n=2)$, and $0.05(95 \% \mathrm{Cl} 0$ to $0.78, p<0.05)$ in a case-control study. Mean/median bone conduction thresholds were respectively $1.19-32.21 / 0-10 \mathrm{~dB}$ higher on all frequencies $(0.5-4 \mathrm{kHz})$ for the $0 \mathrm{M}$-group in four cohort studies $(p<0.05)$. Two other studies reported no statistical test outcomes.

Conclusion Due to the high risk of bias of included studies, effect estimates heterogeneity and suboptimal research designs, no conclusion on the correlation between OM and SNHL can be made. It emphasises the need for future prognostic studies.

\section{INTRODUCTION}

Otitis media $(\mathrm{OM})$ has a great variety in presentation; it can occur transient as acute otitis media (AOM) and OM with effusion, or persistent as recurrent $\mathrm{AOM}(\mathrm{rAOM})$ and chronic suppurative otitis media (CSOM). ${ }^{1}$ It impacts lives worldwide, with global incidence rates estimated at $11 \%$ for $\mathrm{AOM}$ and $5 \%$ for CSOM, of which respectively $51 \%$ and $23 \%$ are children. ${ }^{2}$ The exact incidences of the OM-subtypes vary between populations, depending on social, demographic and genetic factors for instance. ${ }^{1}$

\section{Strengths and limitations of this study}

A minimal otitis exposure of 3 months was adhered to safeguard presence of inner-ear toxin-exposure before outcome assessment.

- A lack of prognostic studies complicates interpretation of effect estimates.

- Heterogeneity of definitions for otitis media and sensorineural hearing loss among studies complicate comparability.

- Recruitment of patients in an otolaryngology setting with audiogram data introduces selection bias.

- Deficits in longitudinal design and methodology limit the quality of our results.

During the acute inflammatory process, $\mathrm{OM}$ can lead to conductive hearing loss (HL). ${ }^{3}$ In children, this transient loss during the acute phase has not been related to a significant risk of delayed speech development or impaired school performance later on. ${ }^{45}$ Though, the inflammatory process of the middle ear can be detrimental to the inner ear as shown in histological and animal studies. ${ }^{6-8}$ During the inflammatory process, toxins can initiate damage to the round window membrane. This leads to diffusion of toxins to the inner ear and leakage of inner ear fluids, resulting in cochlear function loss; a permanent loss. ${ }^{6-8}$ Until, it remains unknown how many episodes of $\mathrm{OM}$, and what duration of disease lead to inner ear HL.

Given the age-related deterioration of inner-ear function, additional OM-related cochlear damage may become more prominent in later life. In observational studies, a statistical significant higher risk of developing permanent conductive and/or sensorineural hearing loss (SNHL) in adulthood has been demonstrated after experiencing CSOM at childhood age. ${ }^{9-11}$ Several studies reported incidence numbers of SNHL up to $23 \%-24 \%$ in patients with CSOM. ${ }^{12}{ }^{13}$ In contrast to other risk factors for SNHL, OM 
is considered treatable by antibiotic or surgical interventions, which are available treatment options in most countries. ${ }^{7}$ Though, up to this day, consensus on the long-term hearing effects of $\mathrm{OM}$ has not been met, which complicates drawing conclusions and making recommendation for clinical care. ${ }^{13}$

Considering the above, we recognise a need for evidence on the effect of $\mathrm{OM}$ on sensorineural hearing levels in time. This knowledge could contribute to establish the best treatment guideline for this common condition, avoiding possible adverse long-term effects. We therefore conducted a systematic review to summarise the evidence on the correlation between rAOM or CSOM and SNHL in time.

\section{METHODS}

\section{Patient and public involvement}

No patients were involved.

\section{Reporting}

We applied the Preferred Reporting Items for Systematic Reviews and Meta-Analyses guideline for this systematic review. $^{14}$

\section{Search strategy}

On 15 January 2021, a systematic search was performed in Embase, PubMed and Cochrane Library databases. No filters were applied. We used search terms and synonyms for the domain (CSOM, rAOM) and outcome (SNHL), including Emtree, and medical subject headings (MeSH) term fields. Used synonyms for the domain were otitis media, (middle) ear infection/inflammation and abbreviations. Used synonyms for the outcome were hearing loss/impairment, deafness, cochlear dysfunction, hypoacusis and inner ear impairment (Search syntax in online supplemental appendix 1). Although SOM did not apply to the study domain, it was included as a synonym to prevent exclusion of relevant articles during the initial search.

\section{Study selection}

Two authors blindly screened studies for inclusion (HBEE, HDvO), and disagreements were resolved by discussion. Where disagreements could not be resolved, a third reviewer (IS or ALS) made the final decision. Prognostic, cohort and cross-sectional studies were included. Cohort studies were categorised in retrospective or prospective study designs. Where this was methodologically unclear, the study was labelled as cohort study. Conference abstracts, or case reports were excluded. In case of an unavailable full text or abstract, the author was contacted to request full text. Reference screening and backwards citation tracking were performed to identify any missed literature. Rayyan was used as screening tool. ${ }^{15}$ Full text screening and data extraction were independently performed by two authors (HBEE, HDvO).
Original studies reporting on hearing outcome of patients of all ages with rAOM or CSOM and a controlgroup were included. Studies including participants with SNHL-related syndromes, cholesteatoma or a history of ear surgery were excluded, as these factors independently cause SNHL. Articles that reported outcomes for several subgroups, of which only a selection met the inclusion criteria, data of that section were extracted and included in the analysis. CSOM was defined as a minimal presence of $\mathrm{OM}$ for three consecutive months or longer. Studies that included patients with OM of more than 3 months or had a minimal follow-up of 3 months were included. These criteria were set to safeguard a minimum period of 3 months in which inner-ear toxin exposure was present, before outcomes were assessed. Studies reporting effect estimates on hearing outcome for both the exposed and control-group were selected. To establish the relation between OM and SNHL, a shift of $>\underline{5} \mathrm{~dB}$ in hearing level between tone audiometric test results was found relevant considering the search range of $5 \mathrm{~dB}$ during these test procedures. $^{16}$

\section{Data collection and analysis}

Quality assessment of the studies

Critical appraisal of included studies was independently performed by two reviewers (HBEE, HDvO) for validity and relevance. The Quality In Prognosis Studies (QUIPS) tool was used to assess risk of bias for prognostic study designs, and the Newcastle-Ottawa Scale (NOS) was used for cohort and case-control studies. ${ }^{17} 18$ To score risk of bias consistently, criteria were predefined for both tools by the authors (online supplemental appendix 2). (HBEE, HDvO) Using these tools, studies could be scored to contain low, moderate or high risk of bias (QUIPS), or to be of good, fair or poor quality (NOS). Differences in the appraisal of studies between the two reviewers in either tool were resolved through discussion.

\section{Data and outcome extraction}

Data on study and patient characteristics, follow-up and bone conduction (BC) hearing outcome of the included patients were independently extracted by two reviewers (HBEE, HDvO). The primary outcome measure of cases and controls was reported in $\mathrm{BC}$ thresholds $(\mathrm{dB})$ per frequency $(0.5-4 \mathrm{kHz})$ and/or average hearing levels. Age, duration of disease and the use of ototoxic ear drops were considered as confounding factors for outcomes of SNHL in groups.

\section{Outcome measures and analyses}

ORs were either extracted directly or calculated by the authors (HBEE, HDvO) if data were sufficient. If an OR could not be extracted or calculated, means and medians were extracted. A p value of $<0.05$ was considered statistically significant. A meta-analysis was performed in case of methodologically homogenous studies. 


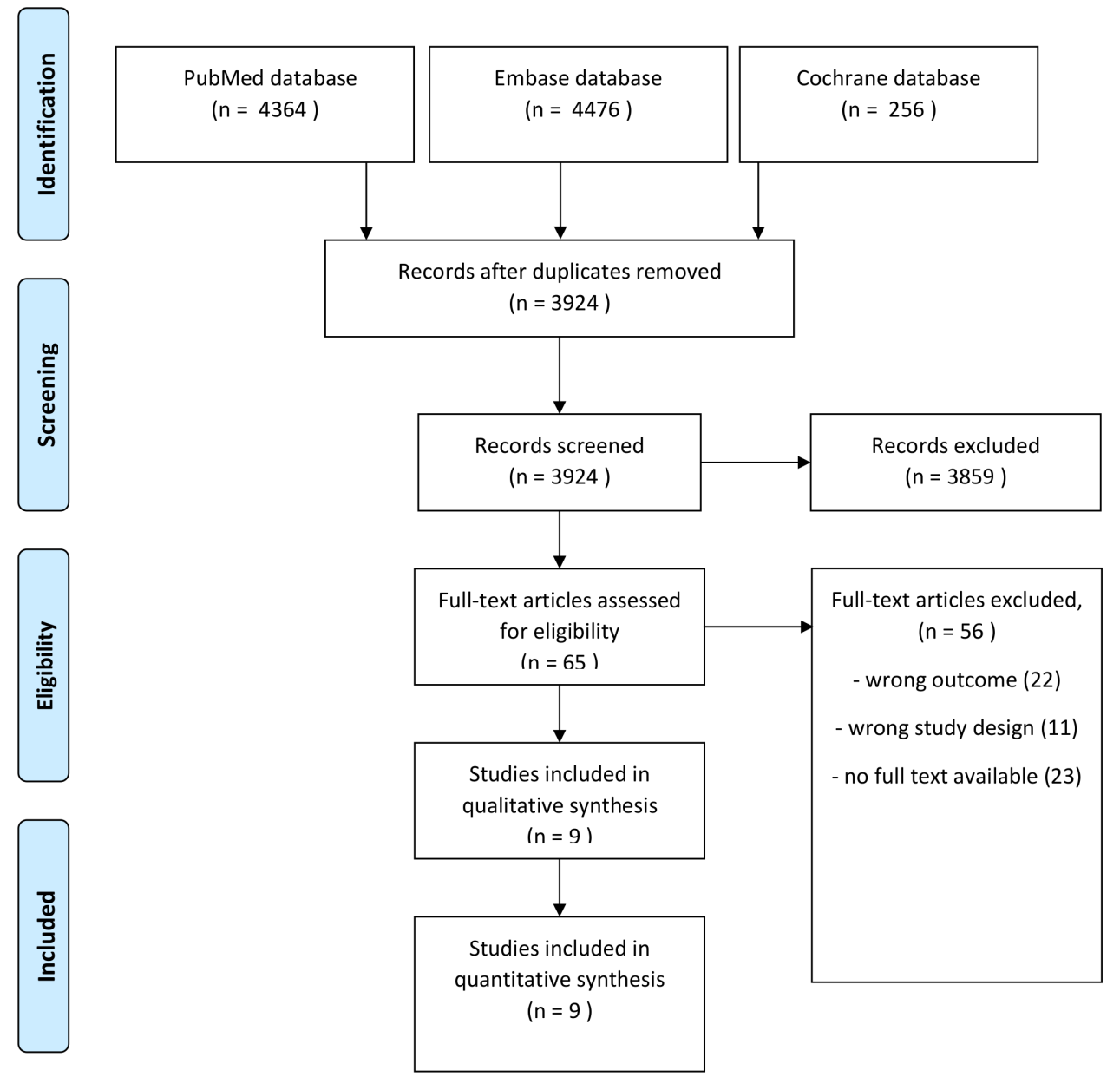

Figure 1 Flow chart for included studies. Last date of search 15 January 2021 Preferred Reporting Items for Systematic Reviews and Meta-Analyses 2009 flow diagram. ${ }^{14}$

\section{RESULTS}

\section{Search strategy and study collection}

The search identified 4168 articles (figure 1). After removal of duplicates, 3725 (89.4\%) studies were screened based on title and abstract, as a result of which 3662 $(98.3 \%)$ studies were excluded. After full-text analysis, 54 articles were excluded based on the outcome $(n=22)$, study design $(n=9)$ or by unavailability of the full text $(n=23)$. No articles were received after correspondence with authors for full text. This resulted in a total of nine articles meeting all inclusion criteria. ${ }^{19-27}$ Seven studies were cohort studies with a retrospective or prospective study design, or not further specified design. ${ }^{19} 202224-2628$ Two studies were case-control studies. ${ }^{23} 27$ No prognostic studies were found. Due to the methodological heterogeneity in included studies, no meta-analysis could be performed.

\section{Quality of the included articles}

Critical appraisal of all studies was performed with the NOS (table 1). The quality of included studies ranged from $\operatorname{good}(\mathrm{n}=5),{ }^{19} 2026-28$ to fair $(\mathrm{n}=2),{ }^{23}{ }^{25}$ and poor $(\mathrm{n}=2){ }^{22} 24$

\section{Selection}

Selection bias was present in all studies, as patients were visiting an otolaryngology department before inclusion, none of the studies included a longitudinal cohort of the general population. Also, there was no objective demonstration that SNHL was not present before inclusion. ${ }^{19-27}$ One study included self-reported diagnosis of OM instead of a doctor diagnosis. ${ }^{23}$ Another study did not document information on recruitment of the cohort. ${ }^{25}$

\section{Comparability}

Most studies excluded patients with a history of ototoxic drug use. ${ }^{192224-27}$ Case-control studies matched cases and controls according to age and gender ${ }^{23}{ }^{27}$ cohort studies used the contralateral ear as control-group. ${ }^{19-22}$ 24-26 Hearing outcomes were not corrected for known or unknow confounding factors in the included studies. ${ }^{19-27}$

\section{Outcome}

Rana $e$ t als study was the only study scoring low risk of bias for the outcome domain. ${ }^{26}$ All other studies did not report information on missing data or loss to follow-up. . $^{10} 23252728$ Two studies could not guarantee a minimum duration of disease of 3 months for all 
Table 1 Risk of bias assessment of included studies according to the Newcastle-Ottawa Quality Assessment Scale

\begin{tabular}{|c|c|c|c|c|c|c|c|c|c|}
\hline $\begin{array}{l}\text { Author } \\
\text { (year) }\end{array}$ & $\begin{array}{l}\text { Amali } \\
(2017)\end{array}$ & $\begin{array}{l}\text { de } \\
\text { Azevedo } \\
(2007)\end{array}$ & $\begin{array}{l}\text { da } \\
\text { Costa } \\
(2009)\end{array}$ & $\begin{array}{l}\text { Kolo } \\
(2011)\end{array}$ & $\begin{array}{l}\text { Krakau } \\
(2017)\end{array}$ & $\begin{array}{l}\text { Paparella } \\
(1984)\end{array}$ & $\begin{array}{l}\text { Рapp } \\
\text { (2003) }\end{array}$ & $\begin{array}{l}\text { Rana } \\
\text { (2019) }\end{array}$ & $\begin{array}{l}\text { Subramaniam } \\
(2020)\end{array}$ \\
\hline \multicolumn{10}{|l|}{ Domain } \\
\hline $\begin{array}{l}\text { Selection } \\
\text { Max: 4하 }\end{array}$ & 3 th & 3 th & 3 th & 3 th & 2 & 3t th & 2 하 & 3t & 3t th \\
\hline $\begin{array}{l}\text { Comparability } \\
\text { Max: } 2\end{array}$ & 1th & 1 th & 1 th & 1하 & 1하 & 1 th & 1 th & 1하 & 1 하 \\
\hline $\begin{array}{l}\text { Outcome } \\
\text { Max: 3t }\end{array}$ & 2 하 & 2 하 & 2 하 & 1t & 2 th & 1th & 2 하 & 3t th & 2 하 \\
\hline $\begin{array}{l}\text { Quality } \\
\text { assessment }\end{array}$ & $\mathbf{G}$ & $\mathbf{G}$ & $\mathbf{G}$ & $\mathbf{P}$ & $\mathbf{F}$ & $\mathbf{P}$ & $\mathbf{F}$ & $\mathbf{G}$ & $\mathbf{G}$ \\
\hline
\end{tabular}

Risk of bias assessment of included studies according to the Newcastle-Ottawa Quality Assessment Scale. ${ }^{17}$

F, fair quality; G, good quality; Max, maximum; $P$

, poor quality.

their included patients. ${ }^{22} 24$ Demographic information of included patients was retrieved from chart reviews. Otoscopy and audiometry were performed by trained personnel using conventional equipment. ${ }^{19-27}$ Only the study of de Azevedo et al reported that audiometry exams were carried out blinded in double by two independent professionals. $^{20}$

\section{Data extraction and study characteristics}

Trial design and study sample

Included studies were published between 1984 and 2019 and pertained to patients from Africa, Asia, Europe, North America and South America (table 2). The sample sizes for the OM-group in cohort and case-control studies ranged from 70 to 607 (controls 70-534) and 13-137 (controls 13-137), respectively. Cohort studies used the contralateral ear as control-group. ${ }^{19-22}$ 24-26 Case-control studies used adults with $<2 \mathrm{AOM}$ episodes until 30 years of age ${ }^{23}$ and volunteers of same age and gender ${ }^{27}$ as control group. Mean duration of disease varied between 6.1 and 12.4 years (range 0.2-42 years) in the four studies reporting it. ${ }^{19202225}$ The mean age of patients was 22-41.5 years (range $0.25-73$ years). Most study populations included both adults and children, except for two studies. $^{2325}$ Paparella et al did not describe the age of included patients, but excluded patients older than 60 years. $^{24}$

\section{Definitions for OM and SNHL}

The included studies handled different inclusion criteria for the OM-group, namely: unilateral otorrhea $>2$ or $>3$ months with a tympanic membrane perforation (TMP),${ }^{1922} 26$ chronic unilateral otorrhea, ${ }^{20}$ inflammation of the middle ear compartment (MEC) of $>3$ months, ${ }^{21}$ rAOM defined as $\geq 3$ episodes of AOM during 6 months or $\geq 4$ episodes during 12 months, ${ }^{23}$ a history of recurrent otorrhea within 3 years before data assembly, ${ }^{24}$ and chronic inflammation of the MEC with recurrent episodes of otorrhea through a TMP. ${ }^{27}$ For Krakau et al, no criteria for inclusion in the OM-group were reported. ${ }^{23}$

Four studies defined their outcome as difference in BC threshold $(\mathrm{dB})$ for cases and controls. ${ }^{19212225}$ Four other studies defined a specific BC threshold level to establish cases with SNHL, namely: $\geq 30 \mathrm{~dB},{ }^{20} \geq 15 \mathrm{~dB} / \geq 30 \mathrm{~dB} /$ any loss at $4 \mathrm{kHz},{ }^{24} \geq 25 \mathrm{~dB},{ }^{26}$ and $\geq 20 \mathrm{~dB} .{ }^{27}$ Papp et $a l^{25}$ did not report a hearing outcome definition to be considered as SNHL.

\section{Results-outcomes}

Three studies (2 cohort studies, 1 case-control study) reported ORs for the presence of SNHL after 3 months or longer exposure to OM (tables 3 and 4). ${ }^{2024} 27$ The other six studies ( 5 cohort studies, 1 case-control studies) reported their outcome as a mean and/or median BC threshold for the OM-group and the control-group (tables 5 and 6). ${ }^{1921-232526}$

\section{Outcomes in cohort studies}

The OR for having SNHL could be extracted or calculated in two cohort studies comparing the contralateral to the diseased ear (table 3$).{ }^{20}{ }^{24}$ Both reported higher ORs for the presence of SNHL after 3 months or longer exposure to OM. Paparella et al reported an OR of 7.86 for a BC loss of $\geq 15 \mathrm{~dB}$ at $\geq 2$ frequencies, 6.49 for $\mathrm{BC}$ loss of $\geq 30 \mathrm{~dB}$ at $\geq 2$ frequencies, and 4.41 for any BC loss at $4 \mathrm{kHz}\left(95 \%\right.$ CI not reported). ${ }^{24}$ For de Azevedo et al, the OR was 3.30 (95\% CI 1.16 to $9.40, \mathrm{p}=0.03) .^{20}$

Five cohort studies reported a mean, ${ }^{192226}$ or both mean and median ${ }^{2125}$ for the BC hearing levels per frequency, stratified per study group (table 5 ). Of those, four studies had a higher mean and/or median BC threshold in the OM-group compared with the control-group for all individually tested frequencies $(0.5-4 \mathrm{kHz}) .^{19} 212226$ Mean and/or median differences between both groups per frequency ranged from 1.19 to $32.21 \mathrm{~dB}(\mathrm{p}<0.05)$ for means and $0-10 \mathrm{~dB}(\mathrm{p}<0.05)$ for medians. ${ }^{192122} 26$ Papp 


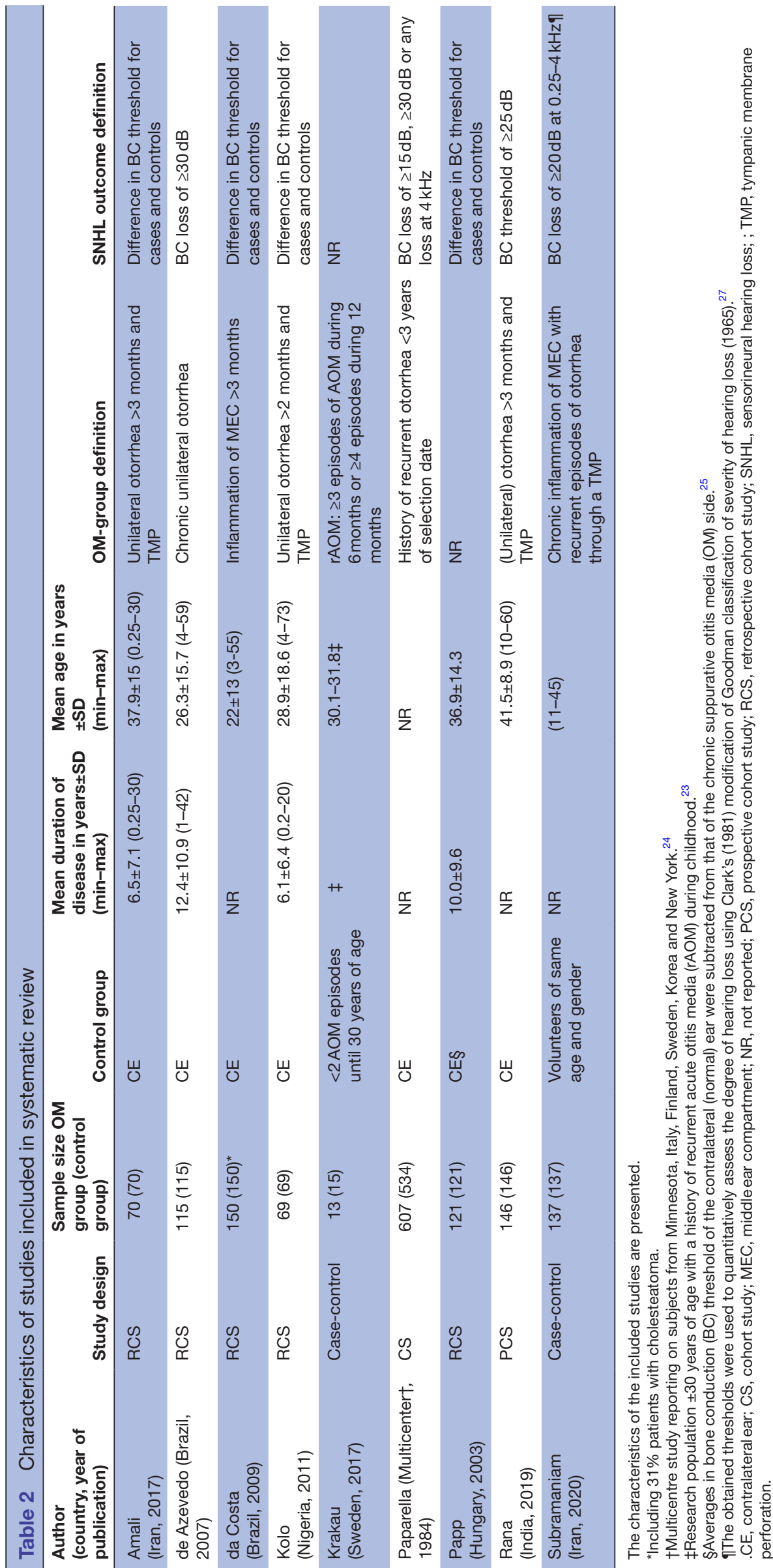


Table 3 Results of studies included in systematic review: OR of having sensorineural hearing loss (SNHL) when exposed to otitis media (OM) in cohort studies

\begin{tabular}{lllll}
\hline Author (year) & Control group & SNHL outcome description & OR (95\% CI) & P value \\
\hline de Azevedo* (2007) & CE & BC loss of $\geq 30 \mathrm{~dB}$ & $3.30(1.16$ to 9.40$)$ & 0.03 \\
Paparella & CE & BC loss $\geq 15 \mathrm{~dB}$ at $\geq 2$ frequencies & $7.86(\mathrm{NR})$ & $<0.05$ \\
$(1984)$ & & BC loss $\geq 30 \mathrm{~dB}$ at $\geq 2$ frequencies & $6.49(\mathrm{NR})$ & $4.41(\mathrm{NR})$ \\
& & BC loss a $4 \mathrm{kHz}$ only & 40.05 & $<0.05$ \\
\hline
\end{tabular}

Relevant results reported in OR for having SNHL when exposed to OM compared with controls (contralateral ear (CE)) 2024 in cohort studies. ${ }^{*}$ OR was calculated manually using the reported data of the study by authors (HBEE, HDvO).

$\mathrm{BC}$, bone conduction.;

et al reported the mean and median $\mathrm{BC}$ threshold for low $(0.5-2 \mathrm{kHz})$ and high $(4 \mathrm{kHz})$ frequencies. The mean differences were higher for the OM-group compared with the control-group, though no statistical significance was determined. ${ }^{25}$

\section{Outcomes in case-control studies}

Subramaniam et al reported data that were sufficient to calculate the OR (table 4: 0.05 (95\% CI 0.00 to 0.78 , $\mathrm{p}=0.03$ ) for SNHL when comparing the patients with OM to healthy volunteers, with SNHL defined as a BC loss of $\geq 20 \mathrm{~dB}$ at $0.25-4 \mathrm{~Hz}$ (table 4$).{ }^{27}$

In one case-control study by Krakau et al, the authors reported median BC thresholds for the OM and controlgroup, stratified for the left and right ear (table 6). The right ear showed a higher BC threshold (difference $10 \mathrm{~dB}$, no $\mathrm{p}$ value) for the OM-group compared with the controlgroup at $3 \mathrm{kHz}$. For all other frequencies, of both the right and left ear, the $\mathrm{BC}$ threshold difference between the groups was $5 \mathrm{~dB}$ or less. ${ }^{23}$

\section{DISCUSSION}

In this study, we described the results of a systematic search on the relation between $\mathrm{AAOM}$ or $\mathrm{CSOM}$ and the occurrence of SNHL in time. Two case-control studies (control-group: patients with non-OM) and seven cohort-studies (controlgroup: contralateral ear) reported hearing outcomes for both the exposed and control-group. ${ }^{19-26}$ The OR for the presence of SNHL after a minimal exposure to OM of 3 months was statistically significantly higher in two cohort studies, ${ }^{20}{ }^{24}$ but lower in one case-control study. ${ }^{27}$ Studies in which no OR was provided or could be calculated, mean and/or median BC thresholds were statistically significantly higher in the OM-group in four out of six studies. Mean or median differences between both groups ranged between $1.19-32.21 \mathrm{~dB}$ and $0-10 \mathrm{~dB}$, respectively. ${ }^{19} 212226$ The other two studies reported differences of $0-5 \mathrm{~dB}$ in mean or median between OM-group and the contralateral ear ${ }^{25}$ or controls, ${ }^{23}$ though did not provide outcomes of statistical testing between groups. Outcomes of included studies should be interpreted cautiously by the small shift in hearing thresholds observed. Besides this, the heterogeneity between studies, the limited quality of included studies and the lack of prognostic studies are all major limitations to draw conclusions about the effect of OM on SNHL.

None of the included articles assessed the effect of duration of the OM on SNHL. A longer period of exposure of the inner ear to inflammation, and therefore to toxins, could increase the portion of patients with SNHL. ${ }^{29}$ Previous population studies analysed the effect of the duration of the OM on hearing levels. Thakur et alstudied 100 cases (15-50 years of age) presenting with unilateral mucosal COM. They found an SNHL incidence of $23 \%$ (hearing level $>20 \mathrm{~dB}$ ), with a statistically significant positive correlation between duration of disease and SNHL. ${ }^{12}$ A comparable SNHL incidence of 24\% in 100 unilateral CSOM cases (aged 11-50 years) was published by Kaur et al, where the SNHL incidence (defined as hearing level $>20 \mathrm{~dB}$ ) increased with the duration of disease (up to $>30$ years). ${ }^{13}$

Besides exposure-time, one should take the following into consideration. Included studies were heterogenous due to varying sample sizes, age of study populations, definitions used for the OM-group, criteria for SNHL and method of reporting of outcome. Recruitment of patients was mostly done in an ENT-setting, and some studies handled absence of an audiogram as exclusion criterion which introduces selection or information bias. For example, Kolo et al excluded patients if they had

Table 4 Results of studies included in systematic review: OR of having sensorineural hearing loss (SNHL) when exposed to otitis media (OM) in case-control studies

\begin{tabular}{lllll}
\hline Author (year) & Control group & SNHL outcome description & OR (95\% Cl) & P value \\
\hline Subramaniam* (2020) $^{*}$ & Volunteers of same age and gender & BC loss of $\geq 20 \mathrm{~dB}$ at $0.25-4 \mathrm{kHz}$ & $0.05(0.00$ to 0.78$)$ & 0.03 \\
\hline
\end{tabular}

Relevant results reported in OR for having SNHL when exposed to OM compared with controls (healthy 'volunteers' of same age and gender $)^{27}$ in case-control studies.

*OR was calculated manually using the reported data of the study by authors (HBEE, HDvO).

$\mathrm{BC}$, bone conduction.; 
Table 5 Results of studies included in systematic review: mean and median bone conduction (BC) thresholds of the otitis media (OM)-group and the contralateral ear

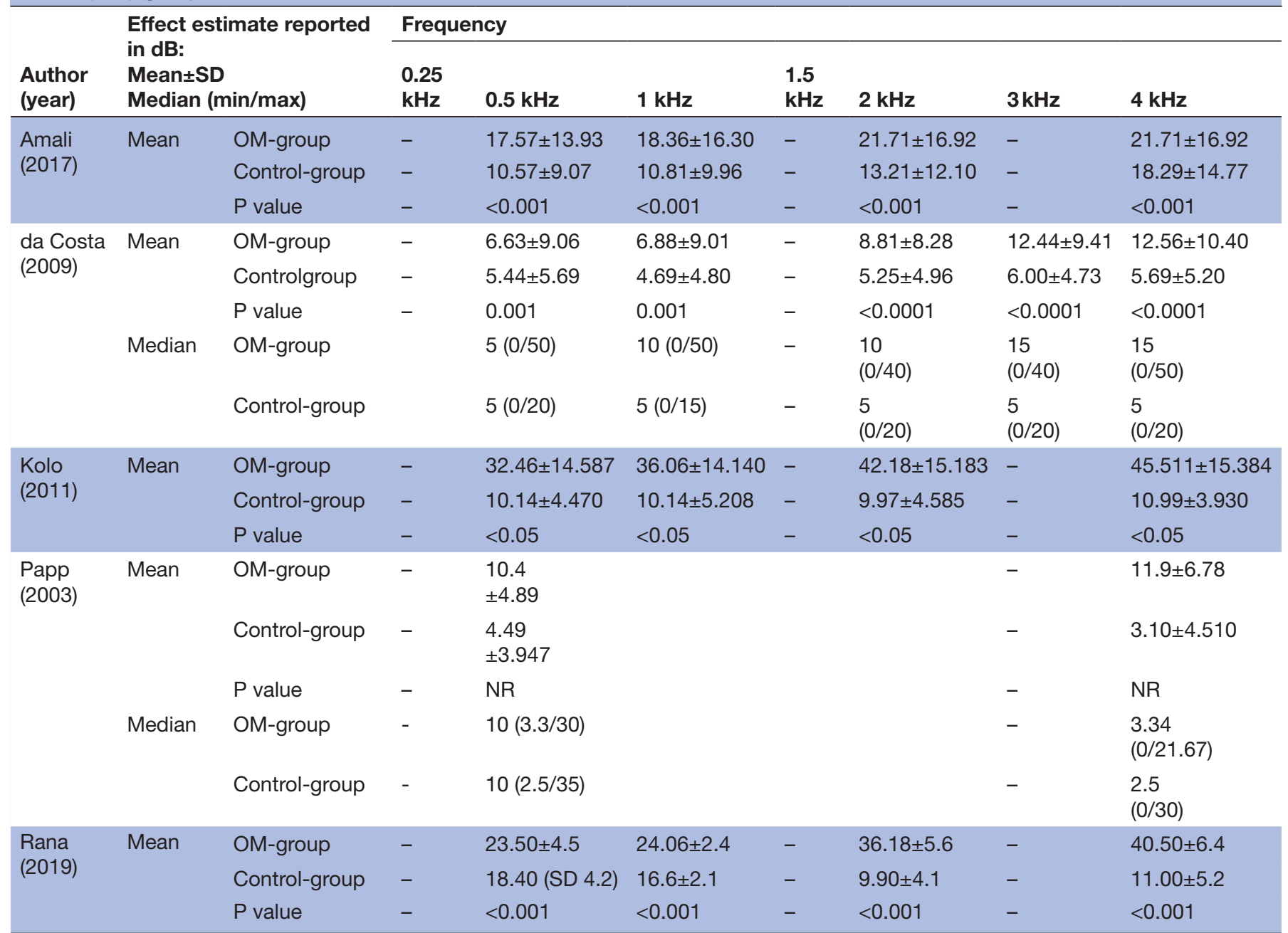

Relevant results of BC thresholds reported in mean and/or median of cohort studies included in systematic review are presented.

Table 6 Results of studies included in systematic review: median bone conduction (BC) thresholds of the otitis media (OM)group and the control-group

\begin{tabular}{|c|c|c|c|c|c|c|c|c|c|}
\hline \multirow[b]{2}{*}{ Author (year) } & \multirow{2}{*}{\multicolumn{2}{|c|}{$\begin{array}{l}\text { Effect estimate reported } \\
\text { in dB: } \\
\text { Mean } \pm \text { SD } \\
\text { Median (min/max) }\end{array}$}} & \multicolumn{7}{|c|}{ Frequency } \\
\hline & & & $0.25 \mathrm{kHz}$ & $0.5 \mathrm{kHz}$ & $1 \mathrm{kHz}$ & $1.5 \mathrm{kHz}$ & $2 \mathrm{kHz}$ & $3 \mathrm{kHz}$ & $4 \mathrm{kHz}$ \\
\hline \multirow[t]{4}{*}{$\begin{array}{l}\text { Krakau } \\
(2017)\end{array}$} & Median & $\begin{array}{l}\text { OM-group } \\
\text { Right ear }\end{array}$ & $\begin{array}{l}5 \\
(0 / 20)\end{array}$ & $\begin{array}{l}5 \\
(0 / 15)\end{array}$ & $\begin{array}{l}0 \\
(-5 / 10)\end{array}$ & $\begin{array}{l}0 \\
(-10 / 25)\end{array}$ & $\begin{array}{l}10 \\
(0 / 20)\end{array}$ & $\begin{array}{l}10 \\
(-5 / 25)\end{array}$ & $\begin{array}{l}0 \\
(-5 / 25)\end{array}$ \\
\hline & & $\begin{array}{l}\text { Control-group } \\
\text { Right ear }\end{array}$ & $\begin{array}{l}0 \\
(-5 / 10)\end{array}$ & $\begin{array}{l}5 \\
(-5 / 10)\end{array}$ & $\begin{array}{l}0 \\
(-10 / 10)\end{array}$ & $\begin{array}{l}0 \\
(-10 / 15)\end{array}$ & $\begin{array}{l}10 \\
(-10 / 40)\end{array}$ & $\begin{array}{l}0 \\
(-5 / 10)\end{array}$ & $\begin{array}{l}5 \\
(-10 / 20)\end{array}$ \\
\hline & & $\begin{array}{l}\text { Control-group } \\
\text { Left ear }\end{array}$ & $\begin{array}{l}5 \\
(-5 / 10)\end{array}$ & $\begin{array}{l}5 \\
(0 / 15)\end{array}$ & $\begin{array}{l}0 \\
(-5 / 10)\end{array}$ & $\begin{array}{l}5 \\
(-5 / 20)\end{array}$ & $\begin{array}{l}10 \\
(0 / 45)\end{array}$ & $\begin{array}{l}0 \\
(-5 / 10)\end{array}$ & $\begin{array}{l}0 \\
(-10 / 15)\end{array}$ \\
\hline & & $P$ value & NR & & & & & & \\
\hline
\end{tabular}

Relevant results of $\mathrm{BC}$ thresholds reported in mean and/or median of case-control studies included in systematic review are presented. 
'incomplete' clinical records or no audiograms. ${ }^{22}$ Age was accounted for by matching cases and controls or by using the contralateral ear. The use of the contralateral ear as non-affected control-group in cohort studies had the advantage of limiting the effect of inter-subject variations. On the other hand, if this ear suffered from infection prior to the study start, but was free of disease during the inclusion process, this could influence outcomes. However, in case-control studies, it could not be guaranteed that their control-group was free of previous OM-exposure. ${ }^{22}{ }^{24}$ For instance, Krakau et al included a patient with 10 self-reported episodes of AOM in the controlgroup. ${ }^{23}$ As stated above, no prognostic studies were included, and a meta-analysis could not be performed due to heterogeneity of reported results. A limitation of the present study is the considerable number of studies of which the full text could not be retrieved.

One could hypothesise that when inflammatory toxins are detrimental to the inner ear, the higher frequencies could be most affected considering their location at the base of the cochlea and in proximity of the inflammatory process in the middle ear. Four out of seven of our included studies reporting mean and/or median BC thresholds show a larger difference in $\mathrm{HL}$ in the higher frequencies (up to $4 \mathrm{kHz}$ ). This is of interest for further studies as it could make people prone for HL in the middle frequency by progression of a high frequency HL by ageing.

The lack of longitudinal study designs and the selected sample of population studied so far hinder strong conclusions. In order to overcome this methodological flaw, studies with a longitudinal design, assessing a random sample of children and adults with and without OM for several decades is necessary. ${ }^{30}$

\section{CONCLUSION}

Considering the high risk of bias and the suboptimal research design of current evidence, no conclusions could be made about the relation between OM and SNHL in time. The high impact of SNHL on daily life, the high prevalence of OM in children and adults, and its potential effect on hearing, underpin the need for longitudinal studies assessing the effect of OM on HL in time.

Acknowledgements This work was supported by the department of Otorhinolaryngology, Head and Neck Surgery and the Brain Center of University Medical Center Utrecht (Utrecht, The Netherlands).

Contributors IS and ALS were involved in conception of the study. HBEE and HDv0 drafted the manuscript, searched and reviewed literature, assessed the quality of the studies, extracted data and performed statistical analysis. All authors contributed to data review and interpretation and manuscript review. All authors have read and approved the final manuscript.

Funding The authors have not declared a specific grant for this research from any funding agency in the public, commercial or not-for-profit sectors.

Competing interests None declared.

Patient consent for publication Not required.

Ethics approval Authors declare there was no conflict of interest. This article does not contain any studies involving human participants or animals performed by any of the authors.
Provenance and peer review Not commissioned; externally peer reviewed.

Data availability statement Data are available upon reasonable request. All data relevant to the study are included in the article or uploaded as supplementary information.

Supplemental material This content has been supplied by the author(s). It has not been vetted by BMJ Publishing Group Limited (BMJ) and may not have been peer-reviewed. Any opinions or recommendations discussed are solely those of the author(s) and are not endorsed by BMJ. BMJ disclaims all liability and responsibility arising from any reliance placed on the content. Where the content includes any translated material, BMJ does not warrant the accuracy and reliability of the translations (including but not limited to local regulations, clinical guidelines, terminology, drug names and drug dosages), and is not responsible for any error and/or omissions arising from translation and adaptation or otherwise.

Open access This is an open access article distributed in accordance with the Creative Commons Attribution Non Commercial (CC BY-NC 4.0) license, which permits others to distribute, remix, adapt, build upon this work non-commercially, and license their derivative works on different terms, provided the original work is properly cited, appropriate credit is given, any changes made indicated, and the use is non-commercial. See: http://creativecommons.org/licenses/by-nc/4.0/.

\section{ORCID iDs}

Hanneke Doremiek van Oorschot http://orcid.org/0000-0001-6858-3984

Inge Stegeman http://orcid.org/0000-0001-5154-7178

\section{REFERENCES}

1 Homøe P, Kværner K, Casey JR, et al. Panel 1: epidemiology and diagnosis. Otolaryngol Head Neck Surg 2017;156:S1-21.

2 Monasta L, Ronfani L, Marchetti F, et al. Burden of disease caused by otitis media: systematic review and global estimates. PLoS One 2012;7:e36226.

3 Rosenfeld RM, Shin JJ, Schwartz SR, et al. Clinical practice guideline: otitis media with effusion (update). Otolaryngol Head Neck Surg 2016;154:S1-41.

4 Engel JAM, Verschuur HP. [The practice guideline 'Otitis media with effusion' (second revision) from the Dutch College of General Practitioners; a response from the perspective of otorhinolaryngology]. Ned Tijdschr Geneeskd 2006;150:2015-7.

5 Silva PA, Chalmers D, Stewart I. Some audiological, psychological, educational and behavioral characteristics of children with bilateral otitis media with effusion: a longitudinal study. J Learn Disabil 1986;19:165-9.

6 Engel F, Blatz R, Kellner J, et al. Breakdown of the round window membrane permeability barrier evoked by streptolysin O: possible etiologic role in development of sensorineural hearing loss in acute otitis media. Infect Immun 1995;63:1305-10.

7 Dobrianskyj FM, Dias Gonçalves Ísis Rocha, Tamaoki Y, et al. Correlation between sensorineural hearing loss and chronic otorrhea. Ear Nose Throat J 2019;98:482-5.

8 Paparella MM, Oda M, Hiraide F, et al. Pathology of sensorineural hearing loss in otitis media. Ann Otol Rhinol Laryngol 1972;81:632-47.

9 Jensen RG, Koch A, Homøe P. The risk of hearing loss in a population with a high prevalence of chronic suppurative otitis media. Int J Pediatr Otorhinolaryngol 2013;77:1530-5.

10 Avnstorp MB, Homøe P, Bjerregaard P, et al. Chronic suppurative otitis media, middle ear pathology and corresponding hearing loss in a cohort of Greenlandic children. Int J Pediatr Otorhinolaryngol 2016;83:148-53.

11 Aarhus L, Homøe P, Engdahl B. Otitis media in childhood and disease in adulthood: a 40-year follow-up study. Ear Hear 2020;41:67-71.

12 Thakur CK, Gupta A, Kumar A. Does mucosal chronic otitis media leads to sensorineural hearing loss. Indian J Otolaryngol Head Neck Surg 2019;205:1-3.

13 Kaur K, Sonkhya N, Bapna AS. Chronic suppurative otitis media and sensorineural hearing loss: is there a correlation? Indian $J$ Otolaryngol Head Neck Surg 2003;55:21-4.

14 Moher D, Liberati A, Tetzlaff J, et al. Preferred reporting items for systematic reviews and meta-analyses: the PRISMA statement. PLoS Med 2009;6:e1000097.

15 Ouzzani M, Hammady $\mathrm{H}$, Fedorowicz Z, et al. Rayyan-a web and mobile APP for systematic reviews. Syst Rev 2016;5:1-10.

16 Katz J. Handbook of Clincal Audiology. 5th Editio. Baltimore: Williams \& Wilkins, 2002. 
17 Deeks J, Dinnes J, D’Amico R. Evaluating non-randomased intervention studies. Heal Tchnol Assess 2003;7.

18 Hayden JA, van der Windt DA, Cartwright JL, et al. Assessing bias in studies of prognostic factors. Ann Intern Med 2013;158:280-6.

19 Amali A, Hosseinzadeh N, Samadi S, et al. Sensorineural hearing loss in patients with chronic suppurative otitis media: is there a significant correlation? Electron Physician 2017;9:3823-7.

20 de Azevedo AF, Pinto DCG, de Souza NJA, et al. Sensorineural hearing loss in chronic suppurative otitis media with and without cholesteatoma. Braz J Otorhinolaryngol 2007;73:671-4.

21 da Costa SS, Rosito LPS, Dornelles C. Sensorineural hearing loss in patients with chronic otitis media. Eur Arch Otorhinolaryngol 2009;266:221-4.

22 Kolo ES, Salisu AD, Yaro AM, et al. Sensorineural hearing loss in patients with chronic suppurative otitis media. Indian J Otolaryngol Head Neck Surg 2012;64:59-62.

23 Krakau M, Dagöö BR, Hellström S, et al. Long-Term hearing outcomes after recurrent acute otitis media during early childhood. Acta Otolaryngol 2017;137:1238-43.
24 Paparella MM, Morizono T, Le CT, et al. Sensorineural hearing loss in otitis media. Ann Otol Rhinol Laryngol 1984:93:623-9.

25 Papp Z, Rezes S, Jókay I, et al. Sensorineural hearing loss in chronic otitis media. Otol Neurotol 2003;24:141-4

26 Rana AK, Singh R, Upadhyay D, et al. Chronic otitis media and its correlation with unilateral sensorineural hearing loss in a tertiary care centre of North India. Indian J Otolaryngol Head Neck Surg 2019;71:1580-5.

27 Subramaniam V, Ashkar A, Rai S. Cochlear dysfunction in chronic otitis media and its determinants. Iran J Otorhinolaryngol 2020;32:79-84.

28 Da CSS, Rosito LPS, Dornelles C. Sensorineural hearing loss in patients with chronic otitis media. Eur Arch Oto-Rhino-Laryngology 2009;266:221-4.

29 Rajput MS-E-A, Rajput MSA, Arain AA, et al. Mucosal type of chronic suppurative otitis media and the long-term impact on hearing loss. Cureus 2020;12:1-8.

30 Gail MH, Altman DG, Cadarette SM, et al. Design choices for observational studies of the effect of exposure on disease incidence. BMJ Open 2019;9:e031031-9. 